\title{
RESEARCH OF SPEED-STRENGTH QUALITIES OF SPECIFIC MUSCLE GROUPS IN ROWERS
}

\author{
Daniela Oronova, Oleg Hristov, Nikola Gospodarski, Rumian Hristov \\ National Sports Academy "Vassil Levski"
}

\begin{abstract}
The power of the stroke in rowing is one of the main factors which determines good sport results. In this relation, increasing of power is a key task during rowers' muscular and strength training.

The main purpose of the current research was to determine speed-strength ability of specific muscle groups of rowers, performing specific strength exercises: bench pull, squat and clean pull.

Methods of the experiment include measurement of velocity and power in different load levels using Gym Aware device and its adjoining software Gym Aware Cloud. The received results demonstrate the specific strength and velocity abilities of the muscular groups which are involved in these movements. It was determined that the maximal power of each of them is achieved at a different point in the range of its working velocity. In squat the maximal power is in the range of the highest velocity achieved with small resistance, in bench pull the maximal power is achieved in the middle of the velocity range and in the clean pull it is achieved at a big resistance and at low velocity. These results arise lots of questions for further discussions.
\end{abstract}

Key words: Rowing, speed-strength qualities, specific muscle groups, specific strength exercises

\section{INTRODUCTION}

Scientific research in the field of rowing can be done in different directions and increasing the power of the stroke cycle is one of them. Rowers' physiology (Hagerman, 1984; Hagerman, 1986; Roth,1991; Seiler, 2008), their movements (Zatsiorsky, 1980; Hristov, 1997; Bompa, 1979; Kleshnev, 2006; Zatsiorsky, 1991), the power they apply on the handle and foot stretchers have been subject of lots of surveys. A number of regression analyses have been made to identify the factors affecting efficiency (Kleshnev, 2006; Nolte, 1985; Seiler, 2008; Soper, 2004) so that the important factors in the rowing training can be determined. These methods, however, do not always provide sufficient information about the reasons why some factors are crucial in the training process. In most cases, the main direction of the analyses of the stroke is to increase the average velocity. The task of an athlete's training is to increase the quality of the energy (power) realized by him so that he can boost the average velocity in a certain mechanical transfer. This means that the successful increasing the power guarantees success.

This is true because according to mechanics when we characterize processes related to movement, such as rowing, power is the integral index the efficiency of drive depends on. 
Power $(\mathrm{P})$ is the product of a certain force $\mathrm{F}$ (N) (load) and velocity $\mathrm{v}(\mathrm{m} / \mathrm{sec})$ needed to relocate this load.

In many cases in sport the load is more or less constant: ball, javelin, tennis racket or baseball bat and other sports equipment. In many sports the personal weight is also important because it is involved in the movement. Each sports expert should be able to analyze their sport and determine how velocity is changed and how the load is measured in the execution of a certain competitive exercise in order to determine the power generated in this exercise.

This is not a simple task because the force of an action (F) is not constant in most sports, but it changes depending on acceleration (a) of the weight involved or the load. We know that $(F=m . a)$ : force is in a direct ratio to the product of the weight involved in the movement and the momentary acceleration of this weight.

Only with a small group of sports, such as power athletics sports, velocity is not so important. It does not matter whether you will lift the barbell within $1 \mathrm{sec}$ or $10 \mathrm{secs}$, the important thing is to do it. In weightlifting, however, it is completely different. If you take a barbell with $60 \%$ of your 1RM (repetition maximum) and try lifting it overhead with a slow movement, you will see it is impossible. You can try throwing a ball or a javelin very far at low speed; try jumping far or high with slow motion or low speed of unfolding your knee. The same principle applies in rowing as well. Try propelling the boat fast by moving the slide slowly and pulling the oars slowly... also impossible. The faster you perform the proper movement, the greater power is generated, and the result is improved. In all cases in sport, the greater the velocity of movement of a piece of sports equipment or the athlete's weight, the more important the power for improving the result from this movement is. In order to seek ways of improving the maximum velocity (of a piece of equipment or an athlete) we should work on improving the possibilities for generating power.

It is important to realize and understand that power is an essential aim in the muscle and strength preparation in all sports. Lots of coaches and athletes still want to put as many plates as possible on the barbell and constantly try to increase their $1 \mathrm{RM}$ in an attempt to increase their maximum strength. But in this way, you will perform your 1RM more slowly than if, for example, performing an exercise with your 10RM. Thus, you will build strong but slow muscles and your actual movement (velocity of execution) will remain slow.

How to determine power?

The applied power for one muscle or a group of muscles propelling a certain joint or a body segment of an athlete depends on the speed-strength qualities of these muscles. The dependence of velocity and strength abilities in muscle activities was determined in the last century by A.V. Hill, 1938. This dependence can be established with the curve force/velocity which determine the power as well. 


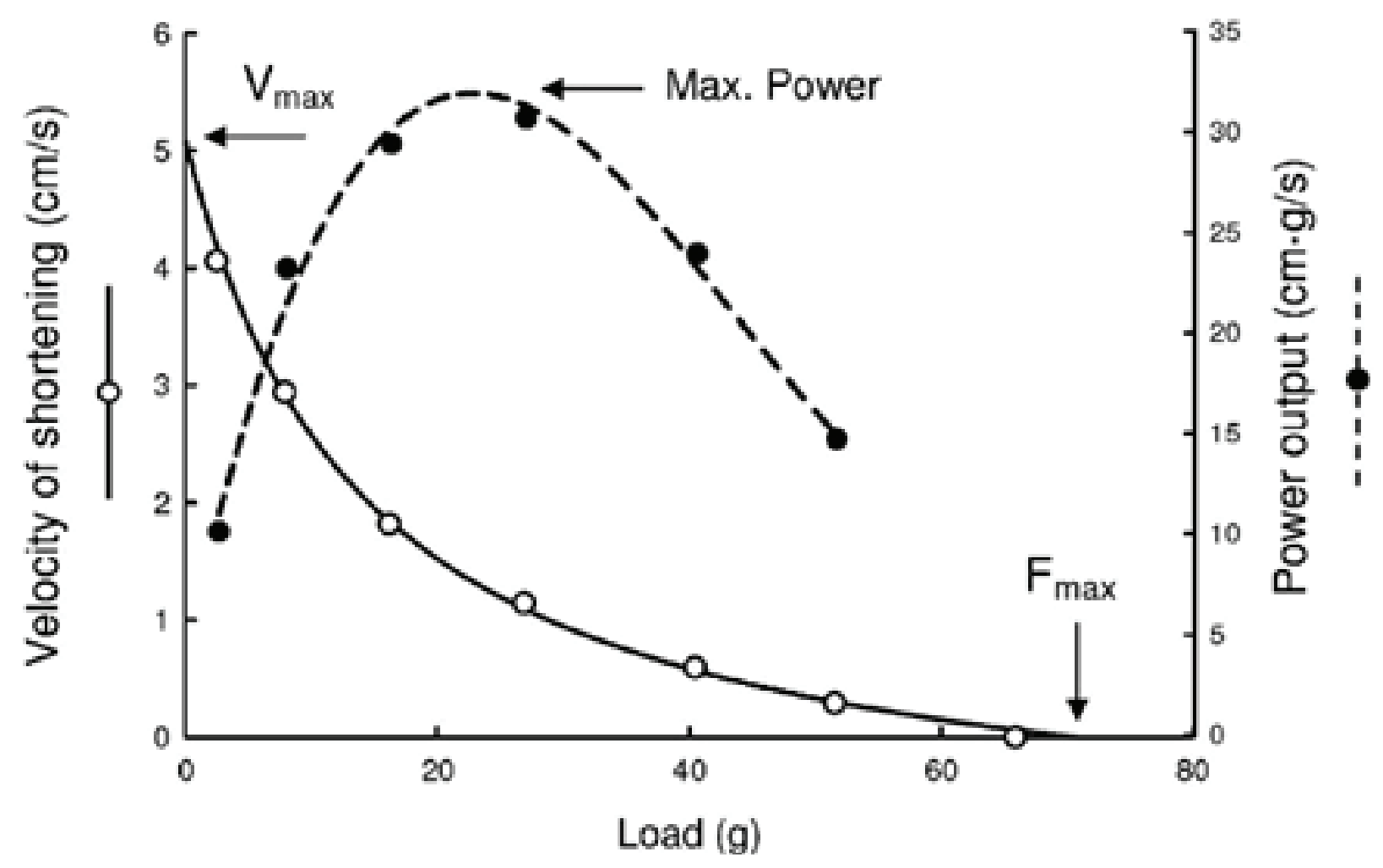

Figure 1. Velocity (solid line and light circles) and power (broken line and dark circles) as (functions of load in an isotonic contraction. Modified by Hill (1938

The curve force/velocity is easy to understand: the heavier the load we overcome, the more slowly the movement will be performed. Examining the movement at different degrees of load in the single joint (unfolding the knee) or multifunctioning joints (pressing with whole leg), we will see this relation in a straight or slightly curved line.

\section{AIM}

To determine the speed-strength qualities of certain muscle groups when rowers execute specific exercises for strength training.

\section{METHODS}

We used a piece of equipment Gym Aware with software Gym AwareCloud to measure the velocity of the moving of an object, in this case a barbell. It is a small box placed on the floor below the barbell. A thin cord, going out of it, is adjusted on the bar. Depending on the velocity of uncoiling or coiling the cord, the speed of the movement of the barbell is recorded. The exactly measured velocity is sent on-line to Apple iOS device where it is presented graphically, and the data are processed and stored in the Internet database.

The research was done among 8 male rowers - students at the National Sports Academy, national competitors with sports experience of $7 \pm 2,4$ years.

We chose specific rowing exercises: bench pull, clean pull and squat.

In order to get a correct curve for the strength-power abilities, we need to make measurements with different weights of the barbell and distribute them evenly within the scope of the suggested 1RM of the athletes. We used an increase of $10 \mathrm{~kg}$. Men started with $40 \mathrm{~kg}$ and continued to 1RM. The athlete should perform 4 repetitions with each weight at maximum speed, and after $60 \%$ of his $1 \mathrm{RM}$ he performs 2 repetitions, and after $80 \%$ - one repetition. 
Sufficient rest time (of minimum $5 \mathrm{~min}$.) between the repetitions was provided to restore the neuromuscular potential.

The software visualizes, calculates and stores the data for peak and mean values of the amplitude of work, velocity and acceleration of the movement. It also calculates the strength and power which were applied.

\section{RESULTS}

After the completion of the test the software makes the individual curve for each athlete (Figure 2). The possible weight of the barbell is automatically extrapolated at maximum volitional isometric contraction (in this case $161.7 \mathrm{~kg}$ ). Note that this is not the realized 1
RM, but a theoretical one! Digital data for the same execution is also presented (Table 1).

Each point on the blue line of the graph demonstrates the relation velocity/load for each attempt with a certain weight. When we know the force (load) and the related velocity it is easy (at least for the software) to calculate the curve of the force/power (the red line).

The curve force/power resembles an upside U-curve with a certain maximum. The upper part of this curve is rather flat, which means there is a certain scope where the power is the closest to maximum, theoretically it is usually $30-70 \%$ of the $1 \mathrm{RM}$. In this case it is about $90 \mathrm{~kg}$ or $75 \%$ of the $1 \mathrm{RM}$.

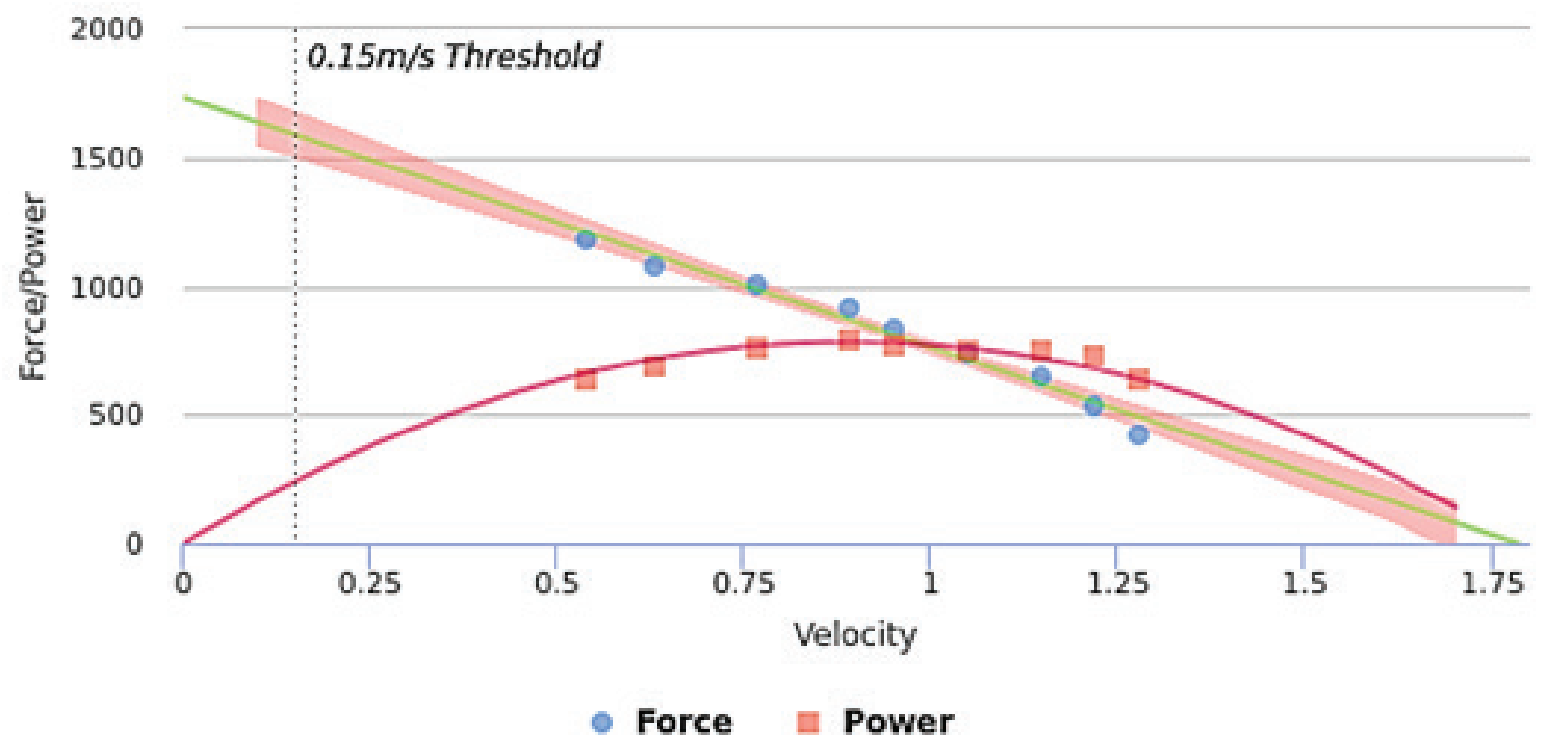

Figure 2. Sample graph of the relation velocity/force and force/power in push press from lying position 
Table 1. Bench pull sample results for one athlete

\begin{tabular}{|c|c|c|c|c|}
\hline \multicolumn{2}{|c|}{$\begin{array}{c}\text { Predictions } \\
\text { 1RM } \\
\text { Load at Max Power }\end{array}$} & \multicolumn{3}{|c|}{$\begin{array}{c}05.03 .2018 \\
161.7 \mathrm{~kg}( \pm 3.6) 0.15 \mathrm{~m} / \mathrm{s} \\
89.6 \mathrm{~kg} 0.89 \mathrm{~m} / \mathrm{s} 783 \mathrm{~W} \\
\end{array}$} \\
\hline Weight & Ratio BM & $\begin{array}{c}\text { Mean } \\
\text { Velocity } \\
(\mathrm{m} / \mathrm{s})\end{array}$ & $\begin{array}{c}\text { Mean Power } \\
\text { (W) }\end{array}$ & Mean Force $(\mathrm{N})$ \\
\hline $40.0 \mathrm{~kg}$ & 0.5 & 1.28 & 633.18 & 423.84 \\
\hline $50.0 \mathrm{~kg}$ & 0.6 & 1.22 & 730.85 & 535.66 \\
\hline $60.0 \mathrm{~kg}$ & 0.7 & 1.15 & 744.32 & 643.74 \\
\hline $70.0 \mathrm{~kg}$ & 0.8 & 1.05 & 750.58 & 734.66 \\
\hline $80.0 \mathrm{~kg}$ & 0.9 & 0.95 & 770.88 & 829.89 \\
\hline $90.0 \mathrm{~kg}$ & 1 & 0.89 & 790.09 & 914.24 \\
\hline $100.0 \mathrm{~kg}$ & 1.2 & 0.77 & 756.7 & 1005.77 \\
\hline $110.0 \mathrm{~kg}$ & 1.3 & 0.63 & 682.88 & 1080.46 \\
\hline $120.0 \mathrm{~kg}$ & 1.4 & 0.54 & 640.18 & 1181.87 \\
\hline
\end{tabular}

A summary of the results about the mean values of the indexes of the attempts where maximum power is realized by the athletes for the whole researched group and the three exercises is presented in Table 2. The lowest power of $701 \mathrm{~W}$ was, quite naturally, achieved in the execution of bench pull where only arms are included. A considerably greater power (average of $1563 \mathrm{~W}$ ) was applied in the execution of squat because of the big muscle groups of the lower limbs. In the combined work of both arms and legs in the exercise clean pull the power is only $920 \mathrm{~W}$, which is a little greater than the power of the arms. The average force for application of the greatest power when executing bench pull is $79 \mathrm{~kg}$ or $74 \%$ of the actually performed $1 \mathrm{RM}$, with the clean pull it is $83.1 \mathrm{~kg}$ or $75.5 \%$, and with the squat it is only $40.1 \mathrm{~kg}$ or $27.9 \%$ of the $1 \mathrm{RM}$.

Table 2. Summary of the results from the three exercises and their variation analysis

\begin{tabular}{|c|c|c|c|c|c|c|c|c|c|c|c|c|c|c|c|c|}
\hline & \multirow[b]{2}{*}{$\begin{array}{c}\text { Body } \\
\text { weight }\end{array}$} & \multicolumn{5}{|c|}{ Bench Pull } & \multicolumn{5}{|c|}{ Clean Pull } & \multicolumn{5}{|c|}{ Squat } \\
\hline & & 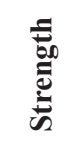 & $\frac{\stackrel{D}{0}}{\frac{0}{0}}$ & : & $\frac{\sum}{\sum^{0}}$ & $\sum_{\beth}$ & 吾 & $\frac{\vec{D}}{0}$ & : & 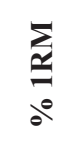 & $\sum_{\beth}$ & 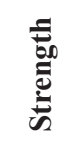 & $\frac{\overrightarrow{8}}{\frac{8}{0}}$ & है & 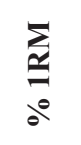 & $\sum_{\beth}$ \\
\hline Average & 98,7 & 79 & 0 , & , 0 & 74,0 & 106,7 & 83,1 & 1,13 & 920,3 & 75,5 & 110,0 & 40,1 & 1,24 & 1563,0 & 27,9 & 143,3 \\
\hline Min & 84,0 & 69,6 & 0,85 & 650,0 & 69,6 & 100,0 & 80,7 & 1,11 & 888,0 & 73,4 & 110,0 & 35,1 & 1,22 & 1424,0 & 27,0 & 130,0 \\
\hline Max & 96,0 & 89,6 & 0,98 & 783,0 & 77,7 & 120,0 & 85,5 & 1,15 & 966,0 & 77,7 & 110,0 & 43,1 & 1,26 & 1708,0 & 28,7 & 150,0 \\
\hline STDEV & 5,2 & 8,2 & 0,1 & 58,6 & 3,3 & 9,4 & 2,0 & 0,0 & 33,2 & 1,8 & 0,0 & 3,5 & 0,0 & 116,0 & 0,7 & 9,4 \\
\hline
\end{tabular}


The results about the velocity at which this maximum power was applied are more interesting. They are graphically presented as a generalized graph for three athletes in Figure 3. The velocity is higher when executing squat - average of $1.24 \mathrm{~m} / \mathrm{sec}$, in the clean pull it is $1.13 \mathrm{~m} / \mathrm{sec}$, and it is the lowest with bench pull $-0.91 \mathrm{~m} / \mathrm{sec}$. It should be noted, however, that the velocity in the bench pull at which the maximum power is applied is in the middle of the scope of work velocities and load. In the clean pull it is at the upper part of this scope or is applied at greater load at low speeds of motion while with the squat we observe the reversed trend - the maximum power is applied at a low load and high speed on the base of the applied one.

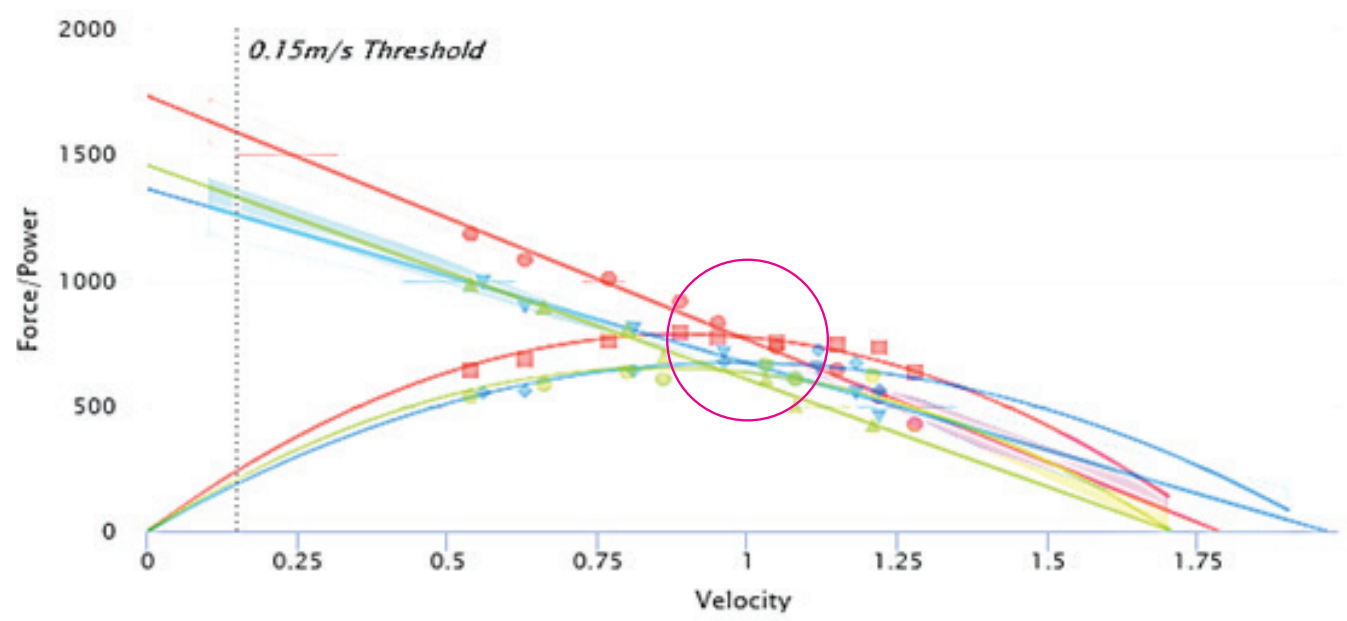

Figure 3a. Optimal velocity for applying maximum power in the bench pull.

The average optimum velocity is $0,91 \mathrm{~m} / \mathrm{sec}$ Optimal velocity for high power is in the midwhen the scope of work speeds for all weight's dle of the scope. ranges from $0,54 \mathrm{~m} / \mathrm{sec}$ to $1,31 \mathrm{~m} / \mathrm{sec}$.

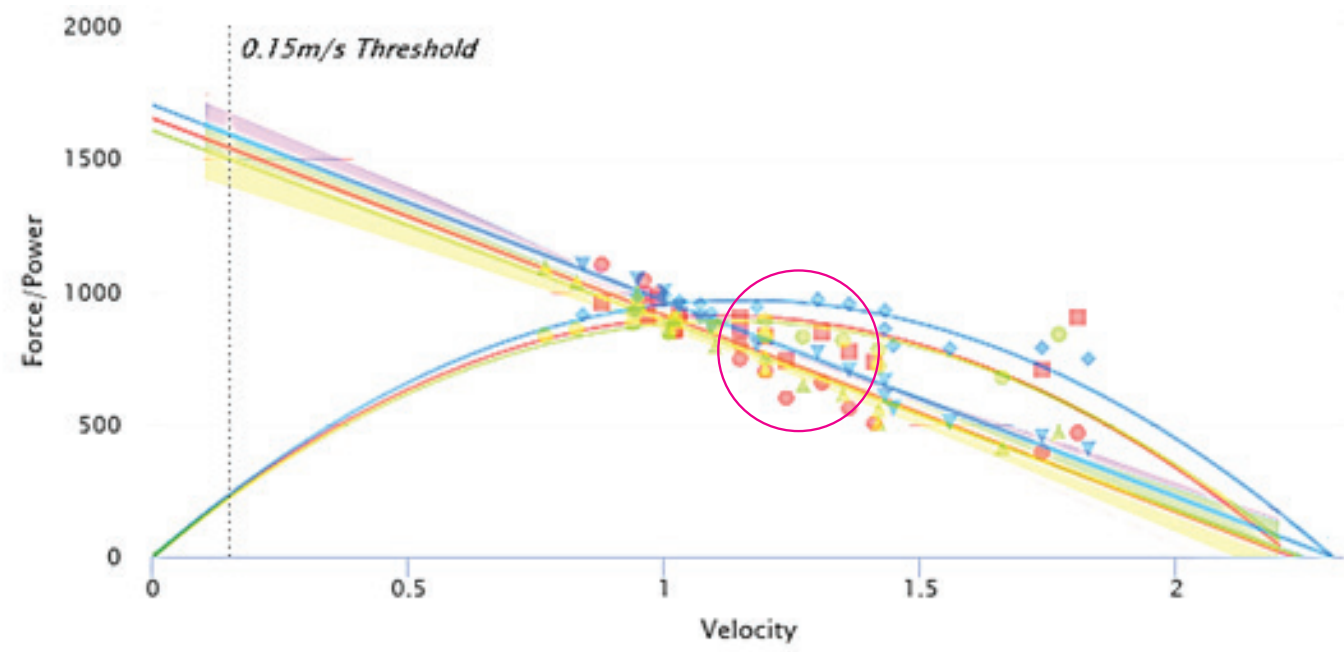

Figure 3b. Optimal velocity for applying maximum power in the clean pull. 
The average optimum velocity is $1,13 \mathrm{~m} /$ sec when the scope of work speeds for all weight ranges from $0,84 \mathrm{~m} / \mathrm{sec}$ to $1,86 \mathrm{~m} / \mathrm{sec}$.
Optimal velocity for high power is at the end of the scope (with the great loads).

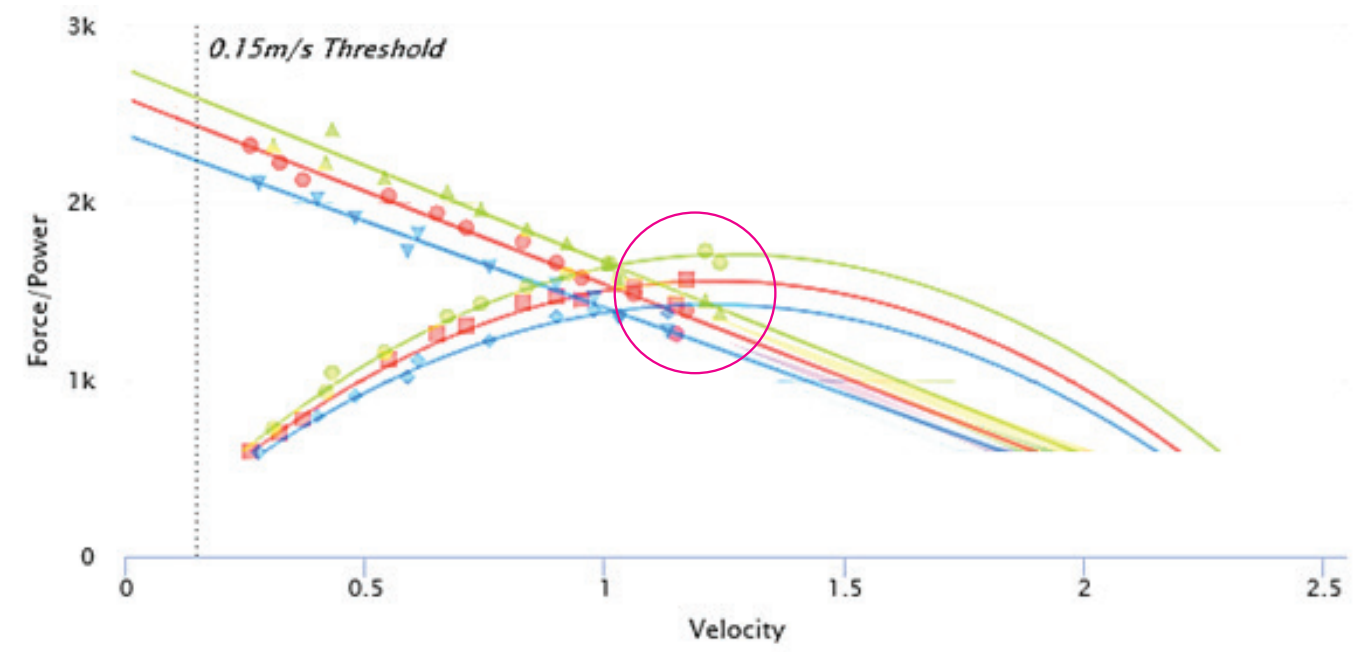

.Figure 3c. Optimal velocity for applying maximum power in the squat

The average optimum velocity is $1,24 \mathrm{~m} /$ sec when the scope of work speeds for all weight's ranges from $0,26 \mathrm{~m} / \mathrm{sec}$ to $1,30 \mathrm{~m} /$ sec. Optimal velocity for high power is at the very beginning of the scope (with the lighter loads).

These results show the specifics of the speed-strength abilities of different muscle groups or a combination of consecutive or simultaneous work of several groups of muscles. However, they set a number of questions such as:

How do we train for strength and which specific speed-strength qualities do we build?

What are the specific requirements for these qualities as regards biomechanics of a particular sport, in this case rowing?
Is a differentiated approach needed when building speed-strength qualities for the different segmented muscle groups in a particular sport?

To what extent does the development of maximum force increase the power of a motor action?

Can a purposeful training program, based on velocity of muscle contractions, change the speed-strength relation in order to increase power?

If we want to improve power, must we engage the fast muscle fibers, and can we transform the qualities of the slow ones which are prevalent and preferred in cycle sports due to their efficiency? 
Despite the questions and issues to be solved in our further research, this method allows us to:

Determine the individual levels of speedstrength qualities of particular muscle groups.

Determine the optimal intensity of power training through immediate feedback upon the execution of the exercises which this piece of equipment offers.

Determine the optimal number of repetitions when a certain speed-strength relation is realized.

\section{REFERENCES}

Bachvarov M. (1976). Akselerometriata kato model za optimizirane, control i razvitie na niakoi strani na skorostno-silovata podgotovka v oblestta na sporta.// Vaprosi na fizicheskata kultura, № 5.

Zatsiorski V.M. I dr. (1980). Biomehanika akademicheskaia greblia: Uchebno pomagalo. - Moskva.

Hristov, R. (1997). Usavarshenstvane na biomehaniqnata struktora na dvigatelnite deistvia pri visoko razriadni sportisti po grebane: Disertacia - Sofia: NSA

Haralampiev A. I dr. (1985). Po vaprosa za uskorenieto na slaida i vrazkata mu s prilozenoto usilie v grebloto.// Vaprosi na fizicheskata kultura, № 1

Bompa T.O. (1979) Rudertechnik und spezial arbaiten. // VII RTC, Werden.

Dudhia Anu. (2001). Basic Physics of Rowing. http://www.atm.ox.ac.uk/rowing/ physics/

Hagerman, F.C. (1984). Applied Physiology of Rowing. // Sport Medicine

Hagerman, F.C. (1986) Defining the energy system. //American rowing.

Kleshnev, V. Propulsive efficiency of rowing. - Canberra: Australian Institute of Sport. Retrieved 5/24/2008, from http://www.biorow.com/Papers_ files/1999PropulsEff03.pdf.1999.

Kleshnev V., (2006). Rowing Biomechanics, www.biorow.com/Papers_files/2000\%20 ISBS\%20Temporal.pdf

Kleshnev, V, et al. (2006). Simple 1+ Dimensional Model of Rowing Mimics Observed Forces and Motions. // Human Movement Science, 2 (25), pp. 192-220.

Koerner, T. et al. (1985) Rudern. - Berlin: Sportverlag.

Nolte, V. (1985) Die Effektivitaetdes Ruderschlages. - Berlin: Bartels \&Wernitz.

Nolte, V (2005). (editor). Rowing Faster. Champaign: Human Kinetics.

Roth, W. (1991). Physiological-Biomechanical Aspects of Load Development and Force Implementation in Rowing. // FISA Coach, Vol.2, No 1.

Schwanitz, P. (2009). Applying Biomechanics to Improve Rowing Performance http://arcrsa.blogspot.com/2009/04/applyingbiomechanics-to-improve-rowing.html

Seiler, S. (1997). The physics and physiology of rowing faster: the stroke. Retrieved 5/24/2008, http://home.hia.no/ stephens/ppstroke.htm.

Soper, S. et. al. (2004). Towards an ideal rowing technique for performance. Sports Medicine, 34 (12), pp. 825-848.

Zatsiorsky, V. et.al. (1991). Mechanics and biomechanics of rowing: A review. // International Journal of Sport Biomechanics, №7, pp. 229-281.

Jovanović, M. And Flanagan, E. (2014). Researched applications of velocity-based strength training. JASC. 22 (2) pp. 58-69.

Harris, N.K., Cronin, J., Taylor K-L., Boris, J. and Sheppard, J. (2010). Understanding position transducer technology for strength and conditioning practitioners. Strength and Conditioning Journal. 32 (4) pp. 66-79. 
Mosey, T. (2011). Power Endurance and athletes: use of velocity-based training in Strength Training Methods of the Australia training athletes. E-book (2nd Ed). pp. 1-39. LW Men's Four. JASC. 19 (1) pp. 9-19

Mann, B. (2013). Developing explosive

\section{Corresponding author:}

Daniela Orinova

Department of ,Water sports“ National Sports Academy "Vassil Levski" Studentski grad, 21, Acad. Stefan Mladenov str. Sofia 1700, Bulgaria E-mail: daniela.oronova@fisa.org 